larger than those prescribed for patients in the prescription sample (none of the doctors reported serious side effects in the returned questionnaires).

No indication for treatment can be singled out as being associated with a particularly high risk. The distribution of indications among the fatal cases and in both prescription samples was very similar. The short-term use of phenylbutazone or oxyphenbutazone for post-traumatic pain, thrombophlebitis, or gout do not seem, on the basis of these results, to be particularly hazardous, although a very much larger series would have to be studied to be sure of this. The main concern, on the contrary, seems to be the use of these two drugs in elderly patients. Indomethacin and co-trimoxazole are appreciable subsidiary causes of blood dyscrasias, the latter being the most common cause of fatal agranulocytosis.

I thank the many general practitioners and consultants who provided the information essential to this inquiry and the doctors who conducted the interviews; the Office of Population Censuses and Surveys; Intercontinental Medical Statistics Limited; the Prescription Pricing Authority; the statistics and research division of the DHSS; and
Mrs Alice Renauld, who typed the manuscript. I am especially grateful to Sir Austin Bradford-Hill, Sir Richard Doll, Professor David Finney, Professor David Price Evans, and Professor Duncan Vere for their critical and most helpful advice in the preparation of this manuscript. Finally, I should like to record my debt to my friend the late Carl de Gruchy, who encouraged me to start this study, and who, most regrettably, did not live to see its conclusion.

\section{References}

1 de Gruchy, G C, Drug-Induced Blood Disorders. Oxford, Blackwell Scientific, 1975 .

2 Toghill, P J, and Wilcox, R G, British Medical fournal, 1976, 1, 502.

${ }^{3}$ Committee on Safety of Drugs, Chloramphenicol. (Adverse Reactions Series No 4). London, HMSO, 1967.

4 Wallerstein, R O, et al, fournal of the American Medical Association, 1969, 208, 2045.

${ }^{5}$ Fowler, P D, Annals of the Rheumatic Diseases, 1967, 26, 344

${ }^{6}$ International Classification of Diseases, 8th revision. Geneva, World Health Organisation, 1967.

\title{
Haemodynamic effects of beta-adrenergic blockade in hyperthyroid patients with and without heart failure
}

\author{
HAMID IKRAM
}

British Medical fournal, 1977, 1, 1505-1507

\section{Summary}

Haemodynamic studies were performed in 10 patients with uncomplicated thyrotoxicosis and seven with thyrotoxic cardiac failure. The cardiac output of those with uncomplicated hyperthyroidism was higher than normal at rest. After $2 \mathrm{mg}$ of intravenous propranolol there was a $13 \%$ fall but the level was still higher than normal. In patients with thyrotoxic cardiac failure the resting cardiac output was normal, but it fell after propranolol by $30 \%$ to subnormal levels.

In both groups there was an increase in right heart pressures and fall in the rate of increase in arterial pressure, which indicated a decrease in myocardial contractility.

These results indicate that increased autonomic activity is a compensatory phenomenon in hyperthyroid heart failure and that its abolition by beta-blocking drugs has a deleterious effect on cardiac function. They are therefore contraindicated in patients with thyrotoxic heart failure.

\section{Introduction}

Autonomic blockade has been advocated as a therapeutic measure in hyperthyroidism because many of the circulatory

\footnotetext{
Department of Cardiology, Princess Margaret Hospital, Christchurch, New Zealand

HAMID IKRAM, MD, FRCPED, consultant cardiologist
}

manifestations of hyperthyroidism resemble those of betasympathetic stimulation. Early workers using non-specific autonomic-blocking agents such as reserpine, ${ }^{1-3}$ methyldopa, ${ }^{4}$ and guanethidine, ${ }^{5-7}$ however, produced equivocal results. When specific beta-receptor antagonists became available they were tested in patients with hyperthyroidism, again with conflicting results. Parenteral administration of pronethalol, ${ }^{8}$ alprenolol, ${ }^{9}$ and sotalol $^{10}$ had no significant effect on most of the circulatory changes. Only intravenous propranolol consistently reduced heart rate and cardiac output. ${ }^{11-13}$ The doses used in these studies, however, are now regarded as cardiotoxic.

Not only is the question of the therapeutic benefit of betablockers in uncomplicated hyperthyroidism unresolved; there is also a lack of information on the effects of beta-blockers in thyrotoxic heart failure. Some workers, extrapolating from observations in uncomplicated hyperthyroidism, have stated that these drugs are beneficial in thyrotoxic heart failure. ${ }^{13} 14$ A survey of reports published in English has, however, failed to show a single study of the effects of beta-blockade in heart failure due to hyperthyroidism.

This study was therefore performed to assess the haemodynamic changes produced by beta-adrenergic blockade in thyrotoxic patients with and without cardiac failure.

\section{Patients and methods}

Seventeen patients were studied. Ten had uncomplicated thyrotoxicosis and seven suffered from thyrotoxic cardiac failure. The diagnosis of hyperthyroidism was based on a suggestive history together with positive radioactive iodine uptake and protein-bound iodine values.

The patients with thyrotoxicosis and heart failure had been extensively screened to exclude any coexisting cardiac disease. Patienfs with a history of cardiac pain or electrocardiographic evidence ot old infarction were excluded from the study. Those with diastolic arterial pressures of over $100 \mathrm{~mm} \mathrm{Hg}$ or with clinical evidence of 
valvular heart disease were also excluded. In doubtful cases formal left and right heart catheterisation was performed to exclude complicating cardiac disease. We were sure therefore that the patients studied had pure thyrotoxic heart failure.

All patients were studied after fasting overnight and without premedication. A Seldinger needle was introduced into a brachial vein. A length of fine polyethylene tubing (PE 50, Clay-Adams and $\mathrm{Co}$ ) was passed through the needle and advanced up the vein into the heart. The position of the catheter was judged by the pressure wave form recorded through it. The catheter passed into the pulmonary artery in all but two of the patients.

Pressures were recorded by means of Bell and Howell transducers on an SE Laboratories multichannel ultraviolet recorder with the zero level being the sternal angle. A short length of PE 60 tubing was introduced into the brachial artery by the Seldinger technique. ${ }^{15}$ Arterial pressure was measured and arterial blood samples were obtained from this site.

Cardiac output was determined by means of the indicator dilution method using indocyanine green dye. The concentration of dye in the blood was detected by a Waters XC-250 Cuvette densitometer and recorded on the multichannel recorder. The densitometer output was also fed into a Sanborn 130 cardiac output computer. This instrument computed the area under the primary circulation curve. The dye curves were calibrated by Sparling's method, ${ }^{16}$ as modified for use with special purpose computers. ${ }^{17}$

The rates of rise of arterial pressure and right ventricular pressure were obtained by differentiating the signal from the appropriate pressure amplifiers by means of an R-C circuit. This system was calibrated by the technique of Knopp. ${ }^{18}$

After baseline pressure recordings and duplicate recordings of cardiac output had been made $2 \mathrm{mg}$ propranolol was administered via the right heart catheter. Fifteen minutes after propranolol administration pressure and cardiac output measurements were repeated.

Statistical analysis was performed using standard techniques.

\section{Results}

The following haemodynamic changes were of particular importance.

Cardiac index-The mean cardiac index $( \pm S D)$ of $6.29 \pm$ $1.80 \mathrm{l} / \mathrm{min} / \mathrm{m}^{2}$ in uncomplicated thyrotoxicosis was above the normal range (3.5-4.5 $\left.1 / \mathrm{min} / \mathrm{m}^{2}\right)$, confirming the existence of a "high output" state. After propranolol there was a definite fall in cardiac index but it still remained raised $\left(5.46 \pm 1.69 \mathrm{l} / \mathrm{min} / \mathrm{m}^{2}\right)$. The difference was not statistically significant $(t=1.06 ; \mathrm{P}=\mathrm{NS})$. In the group with thyrotoxic heart failure the cardiac index was in the normal range to start with $\left(4 \cdot 18 \pm 1.041 / \mathrm{min} / \mathrm{m}^{2}\right)$. After $2 \mathrm{mg}$ of intravenous propranolol it fell to subnormal levels $\left(2.91 \pm 1.18 \mathrm{l} / \mathrm{min} / \mathrm{m}^{2}\right)$. This difference was significant $(t=2.12 ; \mathrm{P}<0.05)$. The average percentage fall was $13.32 \%$ in patients with uncomplicated hyperthyroidism and $30.92 \%$ in those with thyrotoxic heart failure. The magnitude of the fall was significantly different as judged by Student's $t$ test $(t=3.11 ; \mathrm{P}<0.01)$.

Heart rate-The initial rate was higher in the patients without heart failure $(112.4 \pm 19.80$ beats/min) than in those with heart failure $(99 \cdot 14 \pm 8 \cdot 47)$. After propranolol the heart rate fell in both groups. In the uncomplicated cases the fall was modest and not statistically significant (mean $98.0 \pm 18.11$ beats $/ \mathrm{min}$ ). In the other group the fall was much more pronounced and was significant (mean $75.29 \pm 6.18$ beats $\min ; t=6.02 ; \mathrm{P}<0.001)$.

Pulmonary artery diastolic pressure-This measurement is haemodynamically important as it is related to mean left atrial pressure. In those with uncomplicated thyrotoxicosis the mean value was $9.55 \pm 5.05 \mathrm{~mm} \mathrm{Hg}$ increasing to $13.22 \pm 5.95 \mathrm{~mm} \mathrm{Hg}$ after the administration of propranolol.

Mean right atrial pressure-The mean resting right atrial pressure for the uncomplicated group was $1.28 \pm 2.45 \mathrm{~mm} \mathrm{Hg}$. This rose to $2.2 \pm 1.62 \mathrm{~mm} \mathrm{Hg}$ after the administration of propranolol $(t=3.74$; $P<0.005)$. Among patients with heart failure the control pressure was $11.89 \pm 2.49 \mathrm{~mm} \mathrm{Hg}$ and rose to $20.57 \pm 7.27 \mathrm{~mm} \mathrm{Hg}$ after propranolol. The change was statistically significant $(t=2 \cdot 98$; $\mathrm{P}<0.01$ ).

Mean Systemic arterial pressure-The control arterial pressure in uncomplicated cases was $86.8 \pm 18.56 \mathrm{~mm} \mathrm{Hg}$. This fell to $84 \pm$ $32.4 \mathrm{~mm} \mathrm{Hg}$ after intravenous propranolol. In patients with thyrotoxic cardiac failure the control pressure was $85.14 \pm 17.8 \mathrm{~mm} \mathrm{Hg}$ and fell to $78.71 \pm 16.56 \mathrm{~mm} \mathrm{Hg}$ after beta-blockade.

Peak rate of rise of right ventricular pressure-The mean value for this measurement in the group with uncomplicated thyrotoxicosis was $643 \pm 145 \mathrm{~mm} \mathrm{Hg} / \mathrm{s}$. After beta-blockade it fell to $556 \pm$ $72 \mathrm{~mm} \mathrm{Hg} / \mathrm{s}$. Among those with heart failure, the mean value before beta-blockade was $476 \pm 163 \mathrm{~mm} \mathrm{Hg} / \mathrm{s}$. It fell to $347 \pm 115 \mathrm{~mm} \mathrm{Hg} / \mathrm{s}$ after propranolol.

Peak rate of rise of arterial blood pressure-The average resting value in the uncomplicated group was $2495 \pm 983 \mathrm{~mm} \mathrm{Hg} / \mathrm{s}$. After propranolol it fell to $1869 \pm 534 \mathrm{~mm} \mathrm{Hg} / \mathrm{s}$. In those with heart failure the resting value was $1290 \pm 534 \mathrm{~mm} \mathrm{Hg} / \mathrm{s}$. This fell to $928 \pm$ $577 \mathrm{~mm} \mathrm{Hg} / \mathrm{s}$.

\section{Discussion}

The case for sympathetic overactivity being present in uncomplicated thyrotoxicosis has never been secure. Catecholamine levels in animals with hyperthyroidism ${ }^{19}$ and thyrotoxic patients ${ }^{20}$ have been found to be normal. Indeed, Christensen ${ }^{21}$ found that thyrotoxic patients had a lower plasma noradrenaline level than normal. He suggested that sympathetic activity was decreased in hyperthyroidism as a compensatory response to the direct stimulant effects of thyroid hormone on the cardiovascular system. Hence it is not surprising that autonomic blockade in this disease has produced conflicting results.

This study confirms previous findings that in hyperthyroidism intravenous propranolol decreases cardiac rate and output while increasing right heart pressures. These findings, in conjunction with a decline in the peak rate of increase in right ventricular and arterial pressure, indicate a diminution in myocardial "contractility."

The objection to much of the previous work lay in the massive doses of parenteral propranolol that were used. Grossman et al ${ }^{10}$ studied the effects of sotalol, a more recent beta-blocker said to be free from the intrinsic cardiodepressant properties of propranolol. They selected this agent because they considered that the potent cardiodepressant action of propranolol may have led to the conflicting findings concerning the action of betablockade in thyrotoxicosis. They found that some peripheral manifestations of hyperthyroidism (tremor, lid lag, and hyperreflexia) were improved by beta-blockade and that the tachycardia and wide pulse pressure were mediated by betaadrenergic receptors though enhanced ventricular function was independent of them. Although they had not studied patients in heart failure, they stated, "If patients with thyrotoxic heart disease were in congestive heart failure with a fixed stroke volume and a marginal minute cardiac output, reduction of pulse rate without the ability to increase stroke output and thus maintain minute output might be disastrous in the face of continuing high demands of a high oxygen consumption and metabolic rate."

A fixed dose of propranolol was chosen in preference to an individually titrated one for three reasons. Firstly, the only indices of beta-blockade in hyperthyroidism are the circulatory ones being investigated, so to use these would have amounted to begging the question. Secondly, previous workers have used fixed dose schedules. ${ }^{911} 12$ Thirdly, the objective was to compare the responses of the failing and non-failing heart, and these were better assessed by comparing the magnitude of change in circulatory function in response to a standard dose rather than giving varying doses to produce the same cardiovascular end point.

A 2-mg dose of propranolol was selected in this study to avoid the problem of cardiodepression. This dose is effective and safe for treating recurrent ventricular fibrillation complicating acute myocardial infarction ${ }^{22}$ and thyroid "storm." 23 In acute myocardial infarction $2 \mathrm{mg}$ of intravenous propranolol produced negligible myocardial depression. ${ }^{24}$

The resting heart rate fell by about 14 beats/min in patients with uncomplicated thyrotoxicosis. This is comparable to the fall of 7 beats $/ \mathrm{min}$ after intravenous administration of $0.1 \mathrm{mg} / \mathrm{kg}$ that was observed by Robin et al ${ }^{25}$ in normal subjects. This small fall in resting rate is usually attributed to the fact that in 
normal people there is only a low level of sympathetic activity. By analogy, the insignificant fall in resting heart rate suggests there must be only a small level of sympathetic activity in the hyperthyroid patient who is not in cardiac failure. Furthermore, the resting tachycardia in this disease must be due to the thyroid hormone itself.

The propranolol-induced fall in heart rate in patients with hyperthyroidism with cardiac failure was significant, indicating that increased sympathetic activity was present. A similar observation has been made in other forms of cardiac disease. ${ }^{26}$

In a dose of $2 \mathrm{mg}$, which approximates much more to the usual therapeutic dose, propranolol reduced cardiac contractility by only a modest amount in patients with uncomplicated hyperthyroidism. This suggests that in this condition catecholamines are responsible for a relatively small proportion of the enhanced cardiac function, the major portion being due to thyroid hormone. It therefore seems that the only rational indication for beta-blocking drugs in this setting would be to provide symptomatic benefit.

The situation in patients with thyrotoxic cardiac failure is different. The same dose produced a much greater relative fall in cardiac output and rise in venous pressure-that is, cardiac "contractility." This hitherto unreported observation shows that function in the failing thyrotoxic heart is maintained by the sympathetic system just as in cardiac failure from any other cause, since autonomic overactivity is a normal compensatory mechanism. Thus there seems to be no rational basis for giving beta-blockers in this condition; indeed, they are contraindicated.

These observations were made using intravenous propranolol, so they apply only to this mode of administration. The orally administered drug may have different haemodynamic effects in thyrotoxic heart failure.

This work forms part of a thesis accepted for the MD degree of the University of Leeds. The author acknowledges the help of
Dr P B S Fowler and the medical research subcommittee of Charing Cross Hospital, London.

Mrs F Stock kindly typed the manuscript.

\section{References}

${ }^{1}$ Canary, J J, Schaaf, J, and Duffy, B J, jun, New England fournal of Medicine, 1957, 257, 435 .

2 de Groot, W J, et al, fournal of Clinical Investigation, 1961, 40, 1033.

${ }^{3}$ Amidi, M, et al, Circulation, 1968, 38, 229.

${ }^{4}$ Theilen, E O, Wilson, W R, and Tutunji, F J, Metabolism, 1963, 12, 625.

${ }^{5}$ Gaffney, T E, Braunwald, E, and Kaliher, R L, New England fournal of Medicine, 1961, 265, 16.

${ }^{6}$ Waldstein, S S, et al, fournal of the American Medical Association, 1964, $189,609$.

7 Goldstein, S, and Killip, T, Circulation, 1965, 31, 219.

8 Wilson, W R, Theilen, E O, and Fletcher, F W, fournal of Clinical Investigation, 1964, 43, 1697.

${ }^{9}$ Culhed, I, and Parrow, A, Acta Medica Scandinavica, 1968, 184, 235.

${ }^{10}$ Grossman, W, et al, Annals of Internal Medicine, 1971, 74, 869.

11 Howitt, G, and Rowlands, D J, Lancet, 1966, 1, 628.

12 Howitt, G, and Rowlands, D J, American Heart fournal, 1967, 73, 282.

${ }^{13}$ Wiener, L, Stout, B D, and Cox, J W, American fournal of Medicine, 1969, 46, 227.

${ }_{14}$ Canary, J J, New England fournal of Medicine, 1971, 284, 334.

15 Seldinger, S I, Acta Radiologica, 1953, 39, 368.

16 Sparling, C M, et al, in Proceedings of the 3rd European Congress of Cardiology (Rome, 1960), p 595. Amsterdam, Excerpta Medica.

17 Hamer, N A J, et al, British Heart fournal, 1966, 28, 147.

18 Knopp, T J, Rahimtoola, S H, and Swan, H J R, Cardiovascular Research, $1970,4,398$.

${ }^{19}$ Rogoff, J M, and Cortell, R, fournal of Laboratory of Clinical Medicine, $1941,26,981$.

${ }^{20}$ Harrison, T S, et al, Archives of Surgery, 1967, 94, 396.

21 Christensen, N J, Clinical Science and Molecular Medicine, 1973, 45, 163.

${ }^{22}$ Ikram, H, American Heart fournal, 1968, 75, 795.

${ }^{23} \mathrm{Das}, \mathrm{G}$, and Krieger, M, Annals of Internal Medicine, 1969, 70, 985.

${ }^{24}$ Letac, B, and Letournel, J, British Heart fournal, 1975, 37, 624.

${ }^{25}$ Robin, E, et al, Circulation, 1967, 36, 175.

${ }^{26}$ Hamer, J, and Sowton, E, American fournal of Cardiology, 1966, 18, 317.

\title{
Influence of dosage and dietary sodium on the first-dose effects of prazosin
}

\author{
G S STOKES, R M GRAHAM, J M GAIN, P R DAVIS
}

British Medical fournal, 1977, 1, 1507-1508

\section{Summary}

The effects of the first dose of prazosin were assessed in hypertensive patients on different sodium intakes. Patients received 250, 100, or $30 \mathrm{mmol}$ sodium per 24 hours for a week before taking $2 \mathrm{mg}$ or $0.5 \mathrm{mg}$ prazosin. The acute effects of prazosin on blood pressure and pulse rate were milder with a high sodium intake. On the 100-mmol intake symptomatic postural hypotension

Cardiorenal Unit, Medical Research Department, Kanematsu Memorial Institute, Sydney Hospital, Sydney, New South Wales 2000

G S STOKES, MD, FRACP, cardiorenal physician

R M GRAHAM, MB, BS, fellow in cardiorenal diseases

J M GAIN, SRN, SRM, research nurse

$P$ R DAVIS, MB, BS, registrar occurred in five out of seven patients given $2 \mathrm{mg}$ prazosin and in two out of four given a $0.5-\mathrm{mg}$ dose, whereas those taking $2 \mathrm{mg}$ or $0.5 \mathrm{mg}$ and a $250-\mathrm{mmol}$ sodium intake experienced no postural symptoms. These findings indicate that particular care should be taken in starting prazosin treatment in sodium-depleted patients.

\section{Introduction}

Transient postural hypotension is a potential hazard for patients starting treatment with prazosin. ${ }^{12}$ We have attempted to ameliorate this problem by manipulating dietary sodium intake.

\section{Patients and methods}

Eighteen studies were performed on 11 patients, most of whom (see table) had untreated essential hypertension. For a week before each study they received a diet containing $250(n=11), 100(n=6)$, or $30(\mathrm{n}=1) \mathrm{mmol}(\mathrm{mEq})$ of sodium per day. On the first day of the 